DOI: $10.35598 /$ mcfpga.2020.16

\title{
3D Printing in Online Education
}

\author{
Hanna Zavolodko \\ ORCID 0000-0003-0000-8910 \\ dept. System and Information . VO . Kravets \\ NTU " HPI" \\ Kharkiv \\ ann.zavolodko@gmail.com
}

\author{
Nataliia Haidar \\ dept. System and Information . VO . Kravets \\ NTU " HPI" \\ Kharkiv \\ nata.haydar.nh@gmail.com
}

\begin{abstract}
The review object is the subsystem verification and printing 3D-model online learning system mixed type. To do this, a review of analogues, technologies, stages of printing were identified. The aim is to design with IP topics that uses the additive technologies in the educational process. In the given IDEF - diagram describing the function of the system; authentication rules, verification of $3 \mathrm{D}$-models, sending the model to print, selecting a device online, and basic screen forms.
\end{abstract}

Keywords-additive technologies, blended learning, 3dmodel, 3d-printing, rules database, database.

\section{INTRODUCTION}

With the development of technology, new requirements for learning appear and the educational process is transformed Education uses blended learning, part of which is distance learning. The use of additive technologies allows to make the modeling process more meaningful and progressive. Thus, if distance education is the ability to develop a 3D model online and check its loyalty, it optimizes the learning process. [ 1-5 ].

\section{USING 3D PRINTING DURING ONLINE LEARNING}

Learning - the process of transferring knowledge, skills and abilities from teacher to student. To date, there are fulltime, distance and online - learning. They all use interactive tools. Interactive learning - the use of technical means to organize joint activities of students and teachers in order to maintain knowledge, skills and abilities. Distance learning remote independent learning of a student with the use of technical means. Teacher functions - checking the student's work and communicating with the student through forums and chats. Online learning - virtualization of face-to-face learning using interactive tools.

In cooperation with the international project "dComFra Digital competence framework for Ukrainian teachers and other citizens / dComFra (No. 598236-EPP-1-2018-1-LTEPPKA2-CBHE-SP)" a framework of digital competencies for different segments of the population was developed. Today, being competent in the digital field means that the citizen must have competencies in all areas of DigComp. The Digital Competence Framework can help with selfassessment, defining learning goals, identifying learning opportunities, and facilitating job search. In many areas of modern and future professions, the ability to develop a 3D model online and check its accuracy, send the model to print is a necessary task.

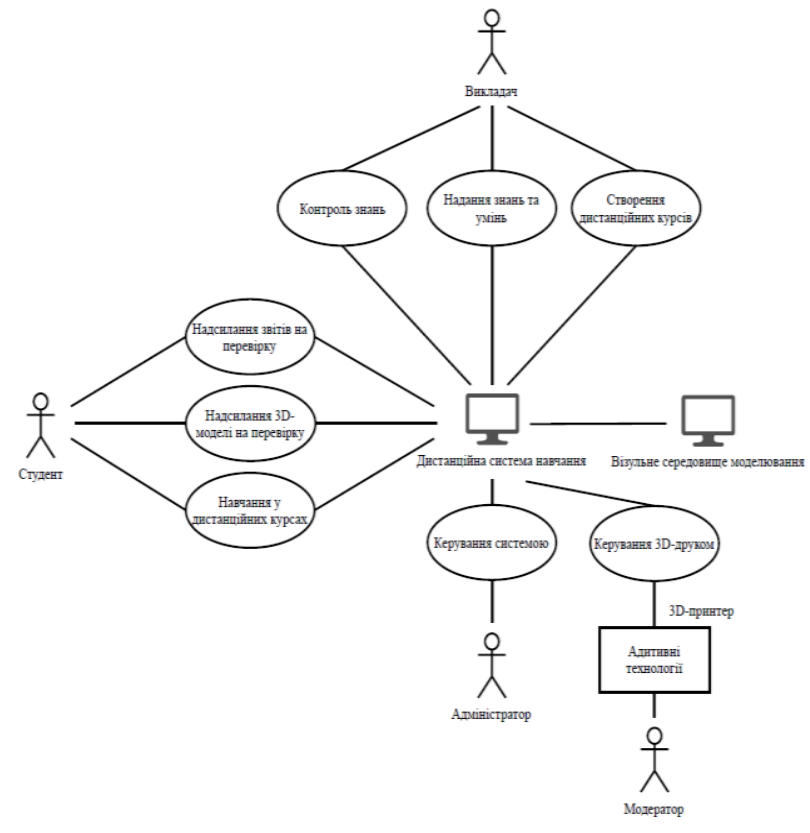

Fig. 1. Block diagram of the relationship of objects.

In a remote system that uses additive technologies, it is possible under the supervision of a moderator and a teacher to perform the functions of checking the 3D model and sending to print [6].

This approach will allow the use of modern devices in distance learning.

Based on the analysis of existing solutions, the stages of 3D printing were identified - the creation of a digital model [7] export of 3D model in STL format, G-code generation, preparation of 3D printer, 3D model printing and finishing of the object.

In general, the system model can be represented using the IDEF0 methodology, in which the input data is a formalized task, the mechanism is an analyst, the control mechanisms are $3 \mathrm{D}$ modeling technologies and printing standards. And at the output the result is a printed model.

The first two levels covered by the system (see Figure 2) are performed in the simulation tools and sent to the system for verification. Validation of the $3 \mathrm{D}$ model involves the 
division into stages, for which the input data can be developed model.

Thanks to modeling technologies, a digital model is created. Such a model must also meet printing standards. Then the model is sent for printing.

The simulated system uses a base of rules based on a production model of knowledge representation.

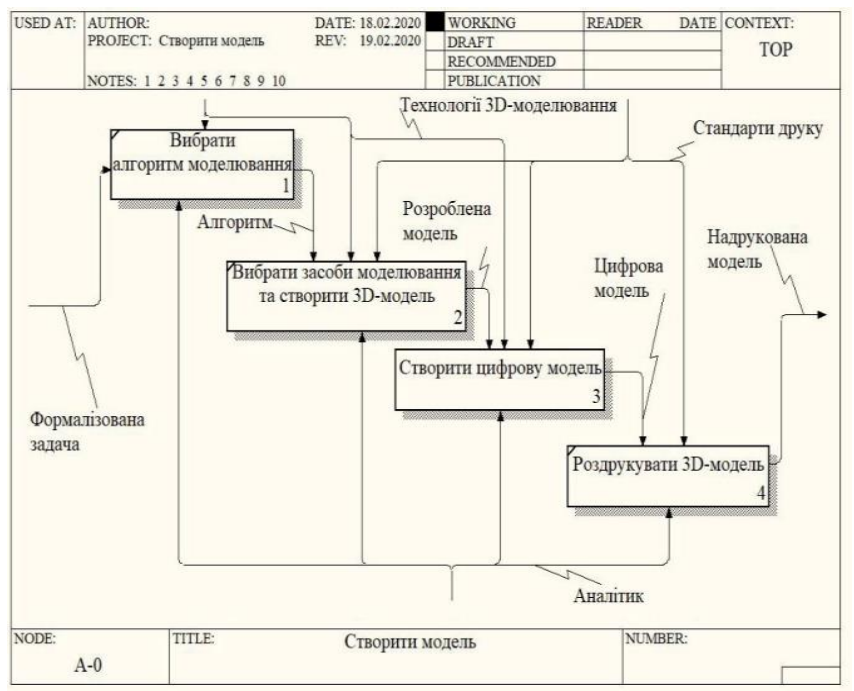

Fig. 2. Simulation algorithm.

Types and subtypes of rules were identified for the correct operation of the system.

For each type of rule, there is a subtype that defines the rules that are involved at a particular stage and are needed for validation.

A file with a 3D model is fed to the input model in the unit for checking the compliance of the additive model. The model is checked by the teacher.

To check, we use the rules that are in the database of rules, which are provided to the teacher in the form of a web page.

If, as a result of checking 3D model validation rules, the model does not meet the requirements, the process exits and the user is sent an error message.

If as a result of checking the rules such as "send the model to print" all the rules are met, the model is passed on to print, if not - the process is completed and users are notified.

In the unit for checking the selection of the print device, a model file that has already been previously tested for $3 \mathrm{D}$ model requirements is fed at the input.
After the user selects the desired device, it is checked whether the selected device meets the requirements for 3D printing. If so - the model is sent for printing, if not - printing is not allowed and the corresponding message is sent to the user.

\section{CONCLUTION}

The development of innovative thinking in students should become a priority of modern education $[8,9]$, and the introduction of new elements in modern learning is inevitable. And given the development of 3D-printing technologies, JSCs are the most promising for the application of visualization in pedagogical activities of online learners and blended learning.

\section{REFERENCES}

[1] Lipnitski L.A., Pilgun T.V. Additive technologies and their perspectives in education. «System analysis and applied information science». 2018;(3):76-82. (In Russ)

[2] M. Palinchak and V. Yzheshchuk, "Basic models of food education in the context of political ideology of the European Union", Geopolitics of Ukraine: history and modernity, vol. 0, no. 219, pp. 108-123, 2017. doi: 10.24144 / 2078-1431.2017.2 (19) .108-123.

[3] I. Pavlova and E. Tarasova, "The role of modern innovative technologies in the educational process", International Journal of Advanced Studies, vol. 8, no. 3, p. 61, 2018. doi: 10.12731 / 2227930x-2018-3-61-78.

[4] V. Povzun, "The role of the modern educational technologies in the development of system thinking of university students", Contemporary Higher Education: Innovative Aspects / Sovremennaia Vysshaia Shkola: Innovatsionny Aspect. Dec 2019, Vol. 11 Issue 4, p. 45-51, 2019. doi: 10.7442/2071-9620-2019-11-4-45-51.

[5] C. Vorotnikova, "Application of modern information technologies in the educational process", european humanities studies: state and society, vol. 3, no., pp. 43-51, 2019. doi: 10.38014/ehs-ss.2019.3-i.04.

[6] I Gibson I., Rosen D. W., Strucker B. Additive Manufacturing Technologies. Rapid Prototyping to Direct Digital Manufacturing. Springer, 2010. $459 \mathrm{p}$

[7] I. Ituarte, N. Boddeti, V. Hassani, M. Dunn and D. Rosen, "Design and additive manufacture of functionally graded structures based on digital materials", Additive Manufacturing, vol. 30, p. 100839, 2019. doi: 10.1016/j.addma.2019.100839.

[8] S. Sysoieva and k. Osadcha, "Status, technologies and prospects of distance learning in higher education in Ukraine", information technologies and learning tools, vol. 70, no. 2, p. 271, 2019. doi: 10.33407 / itlt.v70i2.2907.

[9] I. Gevko, "Application of computer technologies in the educational process of training in higher education institutions", naukovi zapiski, vol. 0, no. 142, pp. 51-59, 2020. doi: 10.31392/nz-npu-142.2019.06.

[10] C. Schelly, G. Anzalone, B. Wijnen and J. Pearce, "Open-Source 3-D Printing Technologies for Education: Bringing Additive Manufacturing to the Classroom", SSRN Electronic Journal, 2015. doi: 10.2139/ssrn.3331158. 